\title{
Pembrolizumab-induced Remission After Failure of Axicabtagene Ciloleucel: Case Report and Literature Review
}

\author{
MARIA DIMOU $^{1}$, AIKATERINI BITSANI ${ }^{1}$, WOLFGANG BETHGE ${ }^{2}$, \\ PANAYIOTIS PANAYIOTIDIS ${ }^{1}$ and THEODOROS P. VASSILAKOPOULOS ${ }^{3}$ \\ ${ }^{1}$ First Internal Medicine Department, Propaedeutic, Hematology Clinical Trial Unit, \\ National and Kapodistrian University of Athens, Laikon General Hospital, Athens, Greece; \\ ${ }^{2}$ Department Hematology \& Oncology Internal Medicine II, University Hospital Tuebingen, Tuebingen, Germany; \\ ${ }^{3}$ Department of Haematology and Bone Marrow Transplantation, \\ National and Kapodistrian University of Athens, Laikon General Hospital, Athens, Greece
}

\begin{abstract}
Background: Failure after CD19-directed chimeric antigen receptor (CAR) T-cell therapy for patients with large B-cell B non-Hodgkin lymphoma, especially when it happens early, is an emerging clinical problem. There are no specific recommendations and therefore treatment of these patients remains empiricaI. Immune checkpoint inhibitors are becoming a therapeutic option for these patients. Case Report: We present a case of a primary mediastinal large B-cell lymphoma who experienced relapse 3.5 months after axicabtageneciloleucel therapy and received pembrolizumab. After four cycles of pembrolizumab, complete metabolic response was confirmed. Treatment was discontinued after the sixth cycle due to immune checkpoint inhibitor-related pneumonitis. The disease remains in remission 8 months after the last pembrolizumab dose. We propose mechanisms of action and optimal duration of pembrolizumab treatment in this setting. Finally, we review the existing literature on the sequential administration of CD19-directed CAR T-cell therapy and immune checkpoint inhibitors. Conclusion: Immune checkpoint inhibitors are a promising treatment option for patients after failure of CD19-directed CAR-T cell therapy.
\end{abstract}

Primary mediastinal large B-cell lymphoma (PMLBCL) is a rare subtype of B-cell non-Hodgkin lymphoma that affects mainly younger patients (1). Treatment outcomes are favorable

This article is freely accessible online.

Correspondence to: Maria Dimou, First Internal Medicine Department, Propaedeutic, Hematology Clinical Trial Unit, National and Kapodistrian University of Athens, Laikon General Hospital, Athens, Greece. Tel: +30 2132060962, e-mail: msdimou@ gmail.com

Key Words: Pembrolizumab, axicabtagene ciloleucel failure, primary mediastinal large B-cell lymphoma. either with first-line R-CHOP (rituximab, cyclophosphamide, doxorubicin, vincristine and prednisone) usually with radiotherapy $(2,3)$ or with DA-EPOCH-R (dose-adjusted etoposide, prednisone, vincristine, cyclophosphamide, doxorubicin and rituximab) usually without radiotherapy (4), with associated 5-year event-free survival $>75-85 \%$ and 5-year overall survival $>85-90 \%(3,4)$.

Despite these favorable responses, relapsed or refractory cases occur either during treatment or shortly after its completion (5). As in diffuse large B-cell lymphoma, salvage chemotherapy followed by autologous stem cell transplant is the standard of care (6) but in many patients the disease is chemorefractory and the outcome of these patients was generally very poor until recently $(6,7)$. Among therapeutic approaches for PMLBCL after a second relapse, only the programmed cell death-1 (PD1) inhibitor pembrolizumab and CD19-directed chimeric antigen receptor (CAR) T-cell therapy with axicabtagene ciloleucel (Axi-Cel) have commercial authorization (the former in the USA and the latter in the USA and EU).

PMLBCL presents frequent amplification and translocation events at the 9p24.1 locus, resulting in tumor expression of the PD1 ligands, PD-L1 and PD-L2 (8). In the KEYNOTE-170 trial, which enrolled patients with relapsed/refractory PMLBCL after at least two treatment lines, pembrolizumab at the dose of $200 \mathrm{mg}$ every 3 weeks provided a $45 \%$ overall response rate (ORR), with $11 \%$ complete response (CR) (8). In the ZUMA-1 trial that evaluated Axi-Cel, in patients with refractory LBCL, eight patients with PMLBCL were included, with no specific information on the outcome of this subgroup (9). However, for the combined PMLBCL and transformed follicular lymphoma subgroup (24 patients), the ORR was $85 \%$ with $70 \% \mathrm{CR}$. Even long-term remissions were observed, with a 2-year progression-free survival rate of $39 \%$ in the ZUMA1 trial (9). Another CAR T-cell product, tisagenlecleucel, has 
also been approved in the USA and EU for patients with relapsed/refractory LBCL after at least two prior treatment lines, having shown ORR of 52\%, including $40 \% \mathrm{CR}$ and $49 \%$ overall survival probability at 12 months for all patients who received an infusion (10).

For patients that experience relapse of LBCL after CAR T-cell therapy, the therapeutic landscape is generally ambiguous. Some existing data show that patients with early relapses ( $<3$ months after CAR T-cell infusion) have very poor outcome, while those with late-onset relapses $(>3$ months after CAR T-cell infusion) have more promising outcomes (11). Among the treatment strategies that have been used in relapse after CAR T-cell therapy are allogeneic bone marrow transplantation, radiation, chemotherapy, lenalidomide and immune checkpoint inhibitors (11).

Relapses after CD19-directed CAR T-cell therapy may be CD19-positive or -negative $(12,13)$. CD19-positive relapses are mainly due to early CAR T-cell loss (i.e., T-cell exhaustion), which can be the result of an overactivated PD1-PDL1 pathway (14). There are emerging data showing a possible synergistic effect of immune checkpoint inhibitors and residual CAR T-cells in cases of relapse in LBCL and B-acute lymphoblastic leukemia $(15,16)$.

We present a case of refractory PMLBCL in a female patient who experienced relapse after initial response to CAR T-cell therapy with Axi-Cel and achieved complete metabolic remission after the administration of pembrolizumab. Moreover, we review the existing relevant literature and speculate on the most appropriate time-point for the sequential administration of CD19-directed CAR T-cell and immune checkpoint inhibitor therapy.

\section{Case Report}

A 41-year-old female patient was diagnosed with PMLBCL after a bronchoscopically acquired biopsy of a mediastinal mass measuring $8 \times 3 \mathrm{~cm}$. The patient had presented severe pain at the left hip a month earlier, for which she underwent whole-body computed tomography (CT). In addition to the mediastinal mass, CT revealed a lytic lesion of the left femoral head, a non-measurable lesion next to the third sacral vertebra, a lesion next to the second rib-sternal junction $(2.9 \times 2 \mathrm{~cm})$ and a mass next to the pancreatic head $(3.6 \times 3.3 \mathrm{~cm})$. The patient also had evening fever $\left(38^{\circ} \mathrm{C}\right)$. The immunohistochemistry of the biopsy showed that the tumor was $\mathrm{CD} 20^{+}, \mathrm{CD}^{+} 0^{+}(30 \%$ of the cells), BCL2 ${ }^{-}, \mathrm{BCL6}^{-}, \mathrm{MUM1}^{-}$, and had a Ki67 index of $80 \%$. Immunohistochemistry for PD1 expression was strongly positive. Fluorescent in situ hybridization examination for rearrangements of $9 \mathrm{p} 24.1$, where the genes for the two PD ligands are located, was also positive. After bronchoscopy, the patient developed thrombosis of the left superior vena cava and was placed on full anticoagulation with fractionated heparin and started pre-phase chemotherapy with

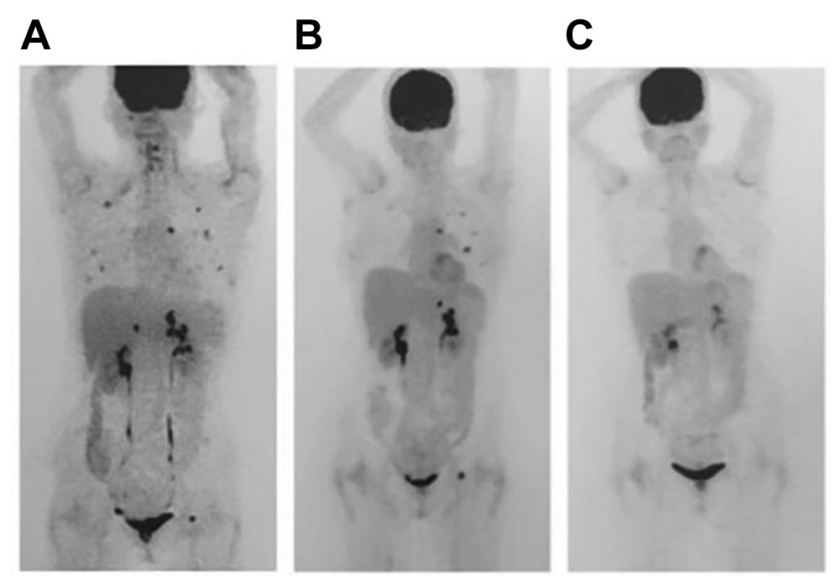

Figure 1. Positron-emission tomography-computed tomography at 3.5 (A) and 5 (B) months after the CD19-directed chimeric antigen receptor $T$-cell infusion and after the fourth cycle of pembrolizumab therapy $(C)$.

dexamethasone and cyclophosphamide. Four days later, the patient presented with 'acute abdomen'. The surgical findings were consistent with duodenal perforation by a bulky nodal mass, which was pathologically proven to be PMLBCL. The patient received monotherapy with rituximab, with some improvement in her clinical condition (defervescence and pain amelioration). A week later she started the R-CHOP-21 combination. She received six cycles, while peripheral blood stem cell collection for a subsequent autologous stem cell transplant took place after the fourth cycle. CT after the end of R-CHOP therapy showed less than partial remission according to Cheson 2007 criteria (17) (less than 50\% reduction of the baseline lesions) and positron-emission tomography (PET) was consistent with a Deauville score of 5 according to the Lugano 2014 guidelines (18), as the mediastinal lesion, the peri-pancreatic mass and the lesion of the left femoral head had maximum standardized ${ }^{18} \mathrm{~F}$ fluorodeoxyglucose uptake (SUVmax) values of 36, 28 and 27.5 , respectively. There were several other areas with metabolic uptake substantially greater than that of the liver.

The patient subsequently received salvage therapy with 2 cycles of R-ESHAP (rituximab, etoposide, doxorubicin, aracytine and prednisolone) with no response. Meanwhile, a new subcutaneous lesion had appeared at the level of the upper part of the sternum. A new biopsy confirmed PMLBCL. The patient again developed fever and severe pain of the left hip causing difficulty in walking. Combination therapy of polatuzumab vedotin with bendamustine and rituximab (Pola-BR) was then given for six cycles, with improvement of the patient's quality of life but with no impact on CT and PET-CT findings.

The patient was subsequently referred to a qualified CAR T-cell center in Germany to receive the Axi-Cel product. After the Axi-Cell infusion the patient developed grade 4 cytokine 
release syndrome and immune effector-cell neurotoxicity syndrome, which were effectively treated. Fourty-eight days after Axi-Cel infusion, disease evaluation with CT and PETCT revealed a CR. PET-CT 2 months later revealed new metabolically active lesions in mediastinal, pararenal and renal areas, with maximum diameter $<1 \mathrm{~cm}$ and SUVmax of 10, 8.2 and 11.5, respectively (Deauville score 5) (Figure 1A). The patient was again referred to his home center for new treatment having progressive disease after Axi-Cel. CAR Tcells were still detected in the peripheral blood. On the patient's return to Greece, 5 months after CAR T-cell infusion, peripheral blood immunophenotyping was performed, which showed profound B-cell aplasia, a pharmacodynamic marker of functional CAR-T persistence $(19,20)$. PET-CT again showed the new metabolic lesions to be more or less unchanged (Figure 1B). We decided to treat the patient with the (off-label for Europe), immune checkpoint inhibitor pembrolizumab at a dose of $200 \mathrm{mg}$ every 3 weeks until progression or unacceptable toxicity. After the fourth cycle of pembrolizumab, PET-CT revealed complete metabolic remission (Figure 1C), again with profound B-cell aplasia in peripheral blood. After the sixth cycle of pembrolizumab, the patient presented severe dyspnea on exertion. A chest CT showed ground-glass morphology in both upper lung lobes. Several bronchoscopic cultures were completely negative for specific pathogens and PET-CT again showed metabolic remission, with mild metabolic uptake (SUVmax $=2.6)$ at the sites of the ground-glass morphology. The diagnosis of immune checkpoint inhibitor-related pneumonitis was established (21). The patient was treated with $0.5 \mathrm{mg} / \mathrm{kg}$ prednisolone and 2 weeks later dyspnea and oxygen need subsided and slow tapering of prednisolone started. Pembrolizumab infusions were held, and the patient was placed under close monitoring with frequent PET-CT. The disease remains in metabolic CR 16 months after Axi-Cel infusion and 8 months after the last infusion of pembrolizumab.

\section{Discussion}

The treatment of relapses after CAR T-cell therapy, especially when they occur early, as in this case, is usually unsuccessful, so that these patients comprise a current unmet medical need (11). In many cases, the reason for relapse can be CAR T-cell exhaustion after an initial expansion, which may be attributed partly to PD1-PDL1 pathway interaction (14). It has been documented that the checkpoint proteins PD1 and PD-L1 are expressed on CAR T-cells and in the tumor microenvironment and are up-regulated after CAR Tcell infusion (22).

Our patient experienced metabolic relapse after metabolic $\mathrm{CR}$ at 3.5 months from the CD19-directed CAR T-cell infusion, however, with CAR T-cells still present, as was concluded from

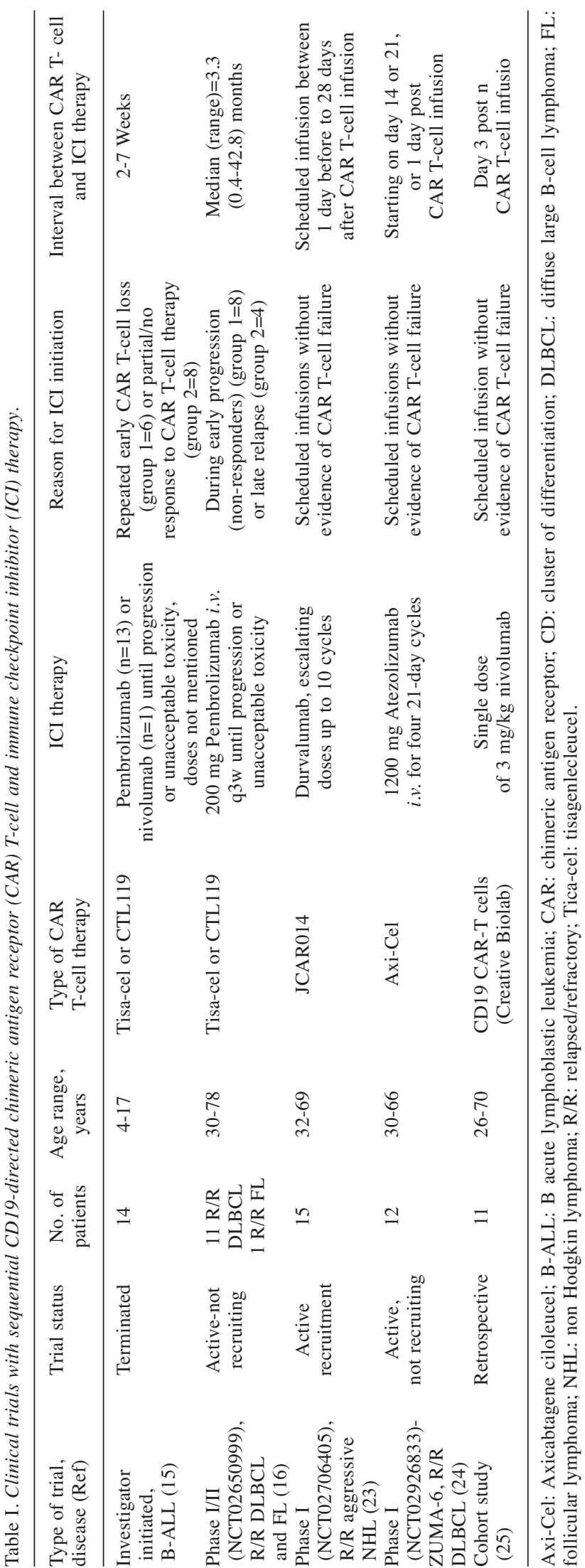


Table II. Responses and adverse events of clinical trials with sequential CD19-directed chimeric antigen receptor T-cell and immune checkpoint inhibitor therapy.

\begin{tabular}{lcc}
\hline Type of trial, disease (Ref) & Disease (Ref) & Response \\
\hline $\begin{array}{l}\text { Investigator initiated, } \\
\text { B-ALL (15) }\end{array}$ & B-ALL (15) & $\begin{array}{c}\text { Group 1: 3/6 re-established B-cell aplasia, no PD } \\
\text { Group 2: 4/8 responded (2 CRs and 2 PRs), } \\
\text { all had bulky extramedullary disease }\end{array}$
\end{tabular}

$\begin{array}{cc}\text { Phase I/II (NCT02650999), } & \text { R/R DLBCL } \\ \text { R/R DLBCL and FL (16) } & \text { and FL (16) }\end{array}$
1 CR, 2 PRs, 1 SD, 7 PDs 9/12 Patients had a re-expansion peak in peripheral blood CAR T-cells
Phase I (NCT02706405), R/R aggressive NHL (23)

Phase I (NCT02926833)ZUMA-6, R/R DLBCL (24)

Cohort study (25)
$\mathrm{R} / \mathrm{R}$ aggressive NHL (23)

R/R DLBCL (24)$$
\text { (24) }
$$

Cohort study (25)

\author{
13 Evaluable patients: ORR=50\% \\ (5 CRs and $1 \mathrm{PR}) \rightarrow$ relapse \\ in 1 patient with CR \\ Continued SD and evidence \\ of regression in 4 more patients \\ 10 Evaluable patients: \\ ORR $=90 \%$ (6 CRs, 3 PRs) \\ CAR T-cell expansion $>2$-fold higher \\ than in patients treated with \\ Axi-Cel alone (ZUMA1) \\ 9/11 Patients responded, with 5 CRs \\ Median PFS=6 months
}

Adverse events

CRS symptoms: $\mathrm{n}=3$

Cytopenia, grade 3/4: $n=4$

Acute pancreatitis: $n=1$

Hypothyroidism: $\mathrm{n}=1$

Arthralgia: $\mathrm{n}=1$

Urticaria: $n=1$

Neutropenia, grade 3/4: $n=3$

CRS, grade 3: $n=1$

Infusion reaction, grade $2: \mathrm{n}=1$,

Fever, grade $1 / 2: n=2$

Fatigue, grade 1/2: $n=2$

Pleural effusion, grade $1: n=1$

Arthralgia, grade 1: $n=1$

CMV infection, unrelated: grade 4: $n=1$

CRS, grade $1 / 2: n=4$; grade $4: n=1$

Neurotoxicity, grade $1: n=1$

Anemia, grade 3: $\mathrm{n}=9$

Encephalopathy, grade 3: $\mathrm{n}=5$

Neutropenia, grade 3/4: $n=5$

CRS, grade $3: n=3$

Neurotoxicity, grade $3: \mathrm{n}=6$

CRS, grades $1 / 2: n=9$

Axi-Cel: Axicabtagene ciloleucel; B-ALL: B acute lymphoblastic leukemia; CAR: chimeric antigen receptor; CMV: cytomegalovirus; CR: complete response; CRS: cytokine-release syndrome; DLBCL: diffuse large B-cell lymphoma; FL: follicular lymphoma; NHL: non Hodgkin lymphoma; ORR: overall response rate; PD: progressive disease; PR: partial response; R/R: relapsed/refractory; SD: stable disease.

the profound B-cell aplasia $(19,20)$. The relapse was metabolic as well as clinical (Figure $1 \mathrm{~A}$ and $\mathrm{B}$ ), as areas of new lymph node disease appeared in the CT scans $(17,18)$.

The favorable outcome of pembrolizumab treatment in this patient can be explained by two different mechanisms. Firstly, PD1 inhibition by pembrolizumab apparently managed to overcome the CAR T-cell exhaustion caused by an overactivated checkpoint pathway, leading to increased numbers of circulating CAR T-cells and re-induction of metabolic CR. However, it should be noted that actual CAR T-cell measurements were not performed. However, continuing profound B-cell aplasia was confirmed. The second mechanism might stem from the fact that pembrolizumab induces responses in a considerable number of patients with relapsed/refractory PMLBCL especially in the setting of increased PD1/PDL1 expression (8). In our patient's case, PD-L1 expression and 9p24.1 rearrangement were strongly positive in the diagnostic tissue. Our patient received only six cycles of pembrolizumab and achieved complete metabolic remission even after the fourth cycle. The treatment with pembrolizumab was discontinued due to pneumonitis, however, the patient remained in metabolic CR for at least 8 months after discontinuation. This favorable outcome with brief pembrolizumab treatment can be attributed to a synergistic effect of the two mechanisms of pembrolizumab action described above.

There are several data emerging from clinical trials that support our findings, which also confirm that PD1/PDL1 pathway inhibition after CD19-directed CAR T-cell therapy may improve the function and persistence of CAR T-cells $(15,16)$. Table I and Table II summarize the most important research data for sequential CD19-directed CAR T-cell and immune checkpoint-inhibitor therapy $(15,16,23-25)$. In some of these trials, the immune checkpoint inhibitor was added only after clinical relapse or in the case of proven CAR T-cell exhaustion $(15,16)$, while in other, immune checkpoint inhibitor infusion was scheduled at specific timepoints after or shortly before the CAR T-cell infusion (2325). Some of these trials are still ongoing.

The data from Table I and Table II, as well as our experience with our patient with PMLBCL, indicate that the sequential infusion of a PD1 inhibitor after CD19-directed 
CAR T-cell therapy may overcome disease relapse or resistance in a considerable number of patients. In particular, the subgroup of patients with PMLBCL who experience relapse after CD19-directed CAR T-cell therapy may enjoy the most favorable outcomes.

Regarding the additive drug-specific toxicity of this treatment strategy, such by the immune checkpoint inhibitorrelated pneumonitis of our patient, perhaps a short-term infusion schedule (e.g., for 4-5 cycles) might induce CD19 CAR T-cell re-expansion without impairing efficacy. Moreover, immune checkpoint inhibitor therapy in cases of lymphoma relapse after CD19-directed CAR T-cell therapy might be more efficacious as a pre-emptive method (not in the setting of relapse or failure of CD19 CAR T-cell expansion) in specific subgroups of patients with high-risk characteristics (e.g., bulky disease) before CAR T-cell infusion. Consequently, sequential infusion with CD19-directed CAR T-cell and immune checkpoint inhibitor in patients with LBCL, and among them those with PMLBCL, deserves further clinical investigation with larger prospective clinical trials.

\section{Conflicts of Interest}

All Authors have nothing to disclose.

\section{Authors' Contributions}

All Authors contributed to the writing of the article.

\section{Acknowledgements}

The Authors thank the patient and her family for permitting us to publish her case details.

\section{References}

1 Liu PP, Wang KF, Xia Y, Bi XW, Sun P, Wang Y, Li ZM and Jiang WQ: Racial patterns of patients with primary mediastinal large B-cell lymphoma: SEER analysis. Medicine (Baltimore) 95(27): e4054, 2016. PMID: 27399089. DOI: 10.1097/MD. 0000000000004054

2 Vassilakopoulos TP, Pangalis GA, Katsigiannis A, Papageorgiou SG, Constantinou N, Terpos E, Zorbala A, Vrakidou E, Repoussis P, Poziopoulos C, Galani Z, Dimopoulou MN, Kokoris SI, Sachanas S, Kalpadakis C, Dimitriadou EM, Siakantaris MP, Kyrtsonis MC, Dervenoulas J, Dimopoulos MA, Meletis J, Roussou P, Panayiotidis P, Beris P and Angelopoulou MK: Rituximab, cyclophosphamide, doxorubicin, vincristine, and prednisone with or without radiotherapy in primary mediastinal large B-cell lymphoma: the emerging standard of care. Oncologist 17(2): 239-249, 2012. PMID: 22282906. DOI: 10.1634/theoncologist.2011-0275

3 Vassilakopoulos TP, Michail M, Papageorgiou S, Kourti G, Angelopoulou MK, Panitsas F, Sachanas S, Kalpadakis C, Katodritou E, Leonidopoulou T, Kotsianidis I, Hatzimichael E, Kotsopoulou M, Dimou M, Variamis E, Boutsis D, Terpos E,
Dimopoulou MN, Karakatsanis S, Michalis E, Karianakis G, Tsirkinidis P, Vadikolia C, Poziopoulos C, Pigaditou A, Vrakidou E, Economopoulos T, Kyriazopoulou L, Siakantaris MP, Kyrtsonis MC, Symeonidis A, Anargyrou K, Papaioannou M, Hatjiharissi E, Vervessou E, Tsirogianni M, Palassopoulou M, Gainaru G, Stefanoudaki E, Zikos P, Tsirigotis P, Tsourouflis G, Assimakopoulou T, Konstantinidou P, A Papadaki H, Megalakaki K, Dimopoulos MA, Pappa V, Karmiris T, Roussou P, Panayiotidis $\mathrm{P}$, Konstantopoulos $\mathrm{K}$ and Pangalis GA: Identification of very low-risk subgroups of patients with primary mediastinal large Bcell lymphoma treated with R-CHOP. Oncologist 26(7): 597-609, 2021. PMID: 33870594. DOI: 10.1002/onco.13789

4 Dunleavy K, Pittaluga S, Maeda LS, Advani R, Chen CC, Hessler J, Steinberg SM, Grant C, Wright G, Varma G, Staudt LM, Jaffe ES and Wilson WH: Dose-adjusted EPOCH-rituximab therapy in primary mediastinal B-cell lymphoma. N Engl J Med 368(15): 1408-1416, 2013. PMID: 23574119. DOI: 10.1056/ NEJMoa1214561

5 Aoki T, Izutsu K, Suzuki R, Nakaseko C, Arima H, Shimada K, Sasaki M, Takizawa J, Mitani K, Igarashi T, Maeda Y, Ishida F, Niitsu N, Ohmachi K, Takasaki H, Nakamura N, Kinoshita T, Nakamura S and Ogura M: Novel prognostic model of primary mediastinal large B-cell lymphoma (PMBL): A multicenter cooperative retrospective study in Japan. Blood 122(21): 638638, 2019. DOI: 10.1182/blood.V122.21.638.638

6 Sehn LH, Antin JH, Shulman LN, Mauch P, Elias A, Kadin ME and Wheeler C: Primary diffuse large B-cell lymphoma of the mediastinum: outcome following high-dose chemotherapy and autologous hematopoietic cell transplantation. Blood 91(2): 717723, 1998. PMID: 9427731.

7 Kuruvilla J, Pintilie M, Tsang R, Nagy T, Keating A and Crump M: Salvage chemotherapy and autologous stem cell transplantation are inferior for relapsed or refractory primary mediastinal large B-cell lymphoma compared with diffuse large B-cell lymphoma. Leuk Lymphoma 49(7): 1329-1336, 2008. PMID: 18604722. DOI: 10.1080/10428190802108870

8 Armand P, Rodig S, Melnichenko V, Thieblemont C, Bouabdallah K, Tumyan G, Özcan M, Portino S, Fogliatto L, Caballero MD, Walewski J, Gulbas Z, Ribrag V, Christian B, Perini GF, Salles G, Svoboda J, Zain J, Patel S, Chen PH, Ligon AH, Ouyang J, Neuberg D, Redd R, Chatterjee A, Balakumaran A, Orlowski R, Shipp M and Zinzani PL: Pembrolizumab in relapsed or refractory primary mediastinal large B-cell lymphoma. J Clin Oncol 37(34): 3291-3299, 2019. PMID: 31609651. DOI: 10.1200/JCO.19.01389

9 Neelapu SS, Locke FL, Bartlett NL, Lekakis LJ, Miklos DB, Jacobson CA, Braunschweig I, Oluwole OO, Siddiqi T, Lin Y, Timmerman JM, Stiff PJ, Friedberg JW, Flinn IW, Goy A, Hill BT, Smith MR, Deol A, Farooq U, McSweeney P, Munoz J, Avivi I, Castro JE, Westin JR, Chavez JC, Ghobadi A, Komanduri KV, Levy R, Jacobsen ED, Witzig TE, Reagan P, Bot A, Rossi J, Navale L, Jiang Y, Aycock J, Elias M, Chang D, Wiezorek J and Go WY: Axicabtagene ciloleucel CAR T-cell therapy in refractory large B-cell lymphoma. N Engl J Med 377(26): 2531-2544, 2017. PMID: 29226797. DOI: 10.1056/ NEJMoa1707447

10 Schuster SJ, Bishop MR, Tam CS, Waller EK, Borchmann P, McGuirk JP, Jäger U, Jaglowski S, Andreadis C, Westin JR, Fleury I, Bachanova V, Foley SR, Ho PJ, Mielke S, Magenau JM, Holte H, Pantano S, Pacaud LB, Awasthi R, Chu J, Anak Ö, 
Salles G, Maziarz RT and JULIET Investigators: Tisagenlecleucel in adult relapsed or refractory diffuse large Bcell lymphoma. N Engl J Med 380(1): 45-56, 2019. PMID: 30501490. DOI: 10.1056/NEJMoa1804980

11 Spiegel J, Dahiya S, Jain M, Nastoupil L, Ghobadi A, Lin Y, Lunning M, Reagan P, Mcguirk J, Deol A, Munoz J, Locke F, Neelapu S, Tamaresis J, Rapoport A, Miklos D and Hill B: Outcomes in large B-cell lymphoma progressing after axicabtagene ciloleucel (Axi-cel): Results from the U.S. Lymphoma CAR-T Consortium. Journal of Clinical Oncology 37(15_suppl): 7517-7517, 2020. DOI: 10.1200/JCO.2019. 37.15_suppl.7517

12 Park JH, Rivière I, Gonen M, Wang X, Sénéchal B, Curran KJ, Sauter C, Wang Y, Santomasso B, Mead E, Roshal M, Maslak $\mathrm{P}$, Davila M, Brentjens RJ and Sadelain M: Long-term followup of CD19 CAR therapy in acute lymphoblastic leukemia. N Engl J Med 378(5): 449-459, 2018. PMID: 29385376. DOI: 10.1056/NEJMoa1709919

13 Bukhari A, El Chaer F, Koka R, Singh Z, Hutnick E, Ruehle K, Lee ST, Kocoglu MH, Shanholtz C, Badros A, Hardy N, Yared J, Rapoport AP and Dahiya S: Rapid relapse of large B-cell lymphoma after CD19 directed CAR-T-cell therapy due to CD19 antigen loss. Am J Hematol 94(10): E273-E275, 2019. PMID: 31342556. DOI: 10.1002/ajh.25591

14 Nie Y, Lu W, Chen D, Tu H, Guo Z, Zhou X, Li M, Tu S and Li Y: Mechanisms underlying CD19-positive ALL relapse after anti-CD19 CAR $\mathrm{T}$ cell therapy and associated strategies. Biomark Res 8: 18, 2020. PMID: 32514351. DOI: 10.1186/ s40364-020-00197-1

15 Li A, Hucks G, Dinofia A, Seif A, Teachey D, Baniewicz D, Callahan C, Fasano C, Mcbride B, Gonzalez V, Nazimuddin F, Porter D, Lacey S, June C, Grupp S and Maude S: Checkpoint inhibitors augment CD19-directed chimeric antigen receptor (CAR) T cell therapy in relapsed B-cell acute lymphoblastic leukemia. Blood 132(Supplement 1): 556-556, 2019. DOI: 10.1182/blood-2018-99-112572

16 Chong E, Svoboda J, Dwivedy nasta S, Landsburg D, Winchell N, Napier E, Mato A, Melenhorst J, Ruella M, Lacey S, June C and Schuster S: Sequential anti-CD19 directed chimeric antigen receptor modified T-cell therapy (CART19) and PD-1 blockade with pembrolizumab in patients with relapsed or refractory Bcell non-Hodgkin lymphomas. Blood 132(Suppl 1): 4198-4198, 2019. DOI: 10.1182/blood-2018-99-119502

17 Cheson BD, Pfistner B, Juweid ME, Gascoyne RD, Specht L, Horning SJ, Coiffier B, Fisher RI, Hagenbeek A, Zucca E, Rosen ST, Stroobants S, Lister TA, Hoppe RT, Dreyling M, Tobinai K, Vose JM, Connors JM, Federico M, Diehl V and International Harmonization Project on Lymphoma: Revised response criteria for malignant lymphoma. J Clin Oncol 25(5): 579-586, 2007. PMID: 17242396. DOI: 10.1200/JCO.2006.09.2403

18 Cheson BD, Fisher RI, Barrington SF, Cavalli F, Schwartz LH, Zucca E, Lister TA, Alliance, Australasian Leukaemia and Lymphoma Group, Eastern Cooperative Oncology Group, European Mantle Cell Lymphoma Consortium, Italian Lymphoma Foundation, European Organisation for Research, Treatment of Cancer/Dutch Hemato-Oncology Group, Grupo Español de Médula Ósea, German High-Grade Lymphoma Study Group, German Hodgkin's Study Group, Japanese Lymphorra
Study Group, Lymphoma Study Association, NCIC Clinical Trials Group, Nordic Lymphoma Study Group, Southwest Oncology Group and United Kingdom National Cancer Research Institute: Recommendations for initial evaluation, staging, and response assessment of Hodgkin and non-Hodgkin lymphoma: the Lugano classification. J Clin Oncol 32(27): 3059-3068, 2014. PMID: 25113753. DOI: 10.1200/JCO.2013.54.8800

19 Kansagra AJ, Frey NV, Bar M, Laetsch TW, Carpenter PA, Savani BN, Heslop HE, Bollard CM, Komanduri KV, Gastineau DA, Chabannon C, Perales MA, Hudecek M, Aljurf M, Andritsos L, Barrett JA, Bachanova V, Bonini C, Ghobadi A, Gill SI, Hill J, Kenderian S, Kebriaei P, Nagler A, Maloney D, Liu HD, Shah NN, Kharfan-Dabaja MA, Shpall EJ, Mufti GJ, Johnston L, Jacoby E, Bazarbachi A, DiPersio JF, Pavletic SZ, Porter DL, Grupp SA, Sadelain M, Litzow MR, Mohty M and Hashmi SK: Clinical utilization of chimeric antigen receptor T cells in B cell acute lymphoblastic leukemia: An expert opinion from the European Society for Blood and Marrow Transplantation and the American Society for Blood and Marrow Transplantation. Biol Blood Marrow Transplant 25(3): e76-e85, 2019. PMID: 30576834. DOI: 10.1016/j.bbmt.2018.12.068

20 Doan A and Pulsipher MA: Hypogammaglobulinemia due to CAR T-cell therapy. Pediatr Blood Cancer 65(4): 10.1002/ pbc.26914, 2018. PMID: 29230962. DOI: 10.1002/pbc.26914

21 Kalisz KR, Ramaiya NH, Laukamp KR and Gupta A: Immune checkpoint inhibitor therapy-related pneumonitis: patterns and management. Radiographics 39(7): 1923-1937, 2019. PMID: 31584861. DOI: $10.1148 / \mathrm{rg} .2019190036$

22 Cherkassky L, Morello A, Villena-Vargas J, Feng Y, Dimitrov DS, Jones DR, Sadelain M and Adusumilli PS: Human CAR T cells with cell-intrinsic PD-1 checkpoint blockade resist tumormediated inhibition. J Clin Invest 126(8): 3130-3144, 2016. PMID: 27454297. DOI: 10.1172/JCI83092

23 Hirayama A, Gauthier J, Hay K, Sheih A, Cherian S, Chen X, Pender B, Hawkins R, Vakil A, Steinmetz R, Phi T, Chapuis A, Till B, Kiem H, Shadman M, Cassaday R, Acharya U, Riddell S, Maloney D and Turtle C: Efficacy and toxicity of JCAR014 in combination with durvalumab for the treatment of patients with relapsed/refractory aggressive B-cell non-Hodgkin lymphoma. Blood 132(Suppl 1): 1680-1680, 2019. DOI: 10.1182/blood-2018-99-116745

24 Jacobson C, Locke F, Miklos D, Herrera A, Westin J, Lee J, Rossi J, Sun J, Zheng L, Avanzi M and Roberts Z: End of phase 1 results from Zuma-6: Axicabtagene Ciloleucel (Axi-Cel) in combination with atezolizumab for the treatment of patients with refractory diffuse large B cell lymphoma. Biology of Blood and Marrow Transplantation 25(3): S173, 2020. DOI: 10.1016/ j.bbmt.2018.12.314

25 Cao Y, Lu W, Sun R, Jin X, Cheng L, He X, Wang L, Yuan T, Lyu $\mathrm{C}$ and Zhao M: Anti-CD19 chimeric antigen receptor T cells in combination with nivolumab are safe and effective against relapsed/refractory B-cell non-Hodgkin lymphoma. Front Oncol 9: 767, 2019. PMID: 31482064. DOI: 10.3389/fonc. 2019.00767

Received July 6, 2021

Revised August 13, 2021

Accepted August 30, 2021 